\title{
RETINAL NEUROPATHOLOGY OF LATE INFANTILE AMAUROTIC IDIOCY*†
}

\author{
BY \\ J. REIMER WOLTER AND RICHARD J. ALLEN \\ From the Department of Ophthalmology and the Pediatric Neurology Unit of the Department of Pediatrics \\ of the University of Michigan Hospital, Ann Arbor, Michigan
}

THE retinal histopathology of amaurotic idiocies, as seen in sections stained with routine technique, as well as some of the histochemical changes are relatively well known (Holmes and Paton, 1925; Givner and Roisin, 1944; MacMillan, 1948). Good knowledge of the neuropathology, however, in this group of diseases is largely limited to the brain (Spielmeyer, 1906). To demonstrate the changes of the ganglion cells, the neurites, dendrites, and the neuroglia of the retina in a typical case of late infantile amaurotic idiocy is the purpose of this paper.

The late infantile type of familial amaurotic idiocy (Bielschowsky, 1913; Batten and Mayou, 1915) is one of a group of hereditary diseases characterized by neural lipid deposition and degeneration of neurons in the brain and retina. It is, strictly speaking, an early juvenile type of amaurotic idiocy (Elwyn, 1953; François, 1961), and usually begins after the second year of life, presenting clinically with epileptic seizures, lack of mental development, weakness and ataxia, blindness, and death usually about 4 years after the first clinical signs. The fundus changes either closely resemble those of the juvenile type of amaurotic idiocy consisting of pigmentary changes and optic nerve atrophy or may exhibit lipoid ganglion cell degeneration resulting in a central cherry-red spot in addition to the pigmentary degeneration (Sorsby, 1958; Duke-Elder, 1940). The latter is described as rare by Duke-Elder (1940). The "cherry-red spot" does not have quite the same appearance as that seen in Tay-Sachs disease; it is less red due to the additional foveal pigment degeneration in the late infantile form and the surrounding white "halo" of swollen ganglion cells is less distinct due to atrophy of many of these cells.

The basic pathology of all types of amaurotic idiocy is a slowly progressive deposition of prelipoid substances and so-called ganglioside (a phosphorus-free carbohydrate containing lipid) in ganglion cells of the brain and retina with subsequent degeneration of the fat-filled cells. In the retina the ganglion cell layer is involved in the infantile and late infantile types. Degenerative changes of the rods and cones combined with degeneration of the pigment epithelium leading to pigment migration and deposition in the retina-somewhat similar to that known from retinitis pigmentosa (Wolter, 1957) - are the basic pathology of the juvenile form and are also found in the late infantile type (Stock, 1908; Batten and Mayou, 1915; Holmes and Paton, 1925; Hagedoorn, 1940; Duke-Elder, 1941; Givner and Roisin, 1944; Elwyn, 1953; François, 1961).

* Received for publication August 19, 1963

† Supported by Grant No. B-2873 of the U.S. Department of Public Health, Education, and Welfare. 


\section{Case Report}

A 44-month-old white boy first came to this University Hospital on May 12, 1958. From the age of 28 months he had had repeated grand mal seizures with frequent myoclonic jerks. Mental and neuromuscular developmental regression became increasingly apparent. The family history appeared to be negative, but a younger brother and two younger sisters later developed the signs of amaurotic idiocy at about the same age.

Neurological Examination.-The boy was mentally obtuse and drooling with very slow responses and slurred speech. Except for a pseudobulbar palsy the cranial nerves including the fundi were normal. He was ataxic and unable to walk or stand without help. The DT reflexes were $3+$ and symmetrical with absent abdominal and cremasteric reflexes and probable extensor plantar responses. Sensory examination was limited to gross modalities and was normal.

Progress.-Within a year the boy became immobile and confined to bed. Irregular pigmentation was observed mainly in the peripheral retina of both eyes. Seizures were frequent and could not be controlled medically. Progressive spasticity became apparent.

With a continuously downhill course the boy had become a severe spastic quadriplegic resembling decerebration by May, 1961 . There was a complete lack of response to anything except withdrawal on pin stimulation. Both fundi showed optic nerve atrophy and a whitish colouration of the posterior retina surrounding a central red spot in the area of the macula. There also was coarse irregular pigmentation peripherally and in the fovea, as well as diffuse irregular pigment all over the fundi.

Death.-This occurred in October, 1961, and a complete post mortem examination including the central nervous system and the eyes established the diagnosis of the late infantile form of amaurotic idiocy (Bielschowsky, 1914).*

\section{Histopathology}

Method.-Both eyes were fixed in neutral formalin and cut in two halves horizontally. One half of each eye was imbedded in paraffin and paraffin sections were stained with haematoxylin and eosin. The retina and optic nerve were isolated from the other halves and sectioned on the freezing microtome. Silver carbonate stains of del Rio Hortega (comp. Scharenberg and Zeman, 1952) were used to stain the neurons and the glia in the retina and optic nerve. All the illustrations are unretouched photomicrographs.

Findings.-The study of the routine sections shows the cornea, filtration angle, anterior chamber, iris, lens, and ciliary body of both eyes of this child to be entirely normal. The retina shows an overall decrease of the number of ganglion cells and thinning of the nerve fibre layer. In the periphery and midperiphery virtually all ganglion cells are gone. Enlarged balloon-like ganglion cells with pink-staining protoplasm and rather small and eccentric nuclei are seen in the posterior retina and especially around the fovea. The rods and cones are virtually absent in the peripheral retina as well as in the macular area and there is patchy deposition of clumps of pigment granules in the outer retinal layers in these zones. In the central retina around the fovea and optic disc the rods and cones are much better preserved. However, they also show some atrophy and irregularity as well as some diffuse deposition of pigment. The pigment epithelium is of very irregular pigmentation and shows areas of atrophy adjacent to the larger pigment deposits in the outer retina. The optic nerve shows definite atrophy, but-as is usual in cases of clinical optic nerve atrophy - many nerve fibres remain in its bundles.

Silver staining of flat-frozen sections of the retinae of these eyes permitted the following neuropathological observations:

(1) The inner limiting membrane is thickened. Fig. 1 (opposite) shows the mosaic of the foot plates of the brush-like inner ends of Müller's radial fibres in the thickened inner

\footnotetext{
* Detailed information on the neuropathological findings in the brain of this and similar cases will be given in a forthcoming paper on infantile dementias by Allen, McCusker, and Tourtellotte (in preparation).
} 
limiting membrane. The pattern of these foot plates is somewhat coarser than normal. The nerve fibre layer is thinned and there are fewer nerve fibres in it than normal. Fig. 2 shows a portion of a transitional section of the retina between fovea and disc. Enlarged lipid-filled ganglion cells ( $\mathrm{g}$ ) are seen on the left side of the photograph. A counterstain with "oil-red $\mathrm{O}$ " is used in this section and all the ganglion cells are stained a light red. The neurites (n) of these ganglion cells are seen to enter the nerve fibre layer on the right side of the photograph.

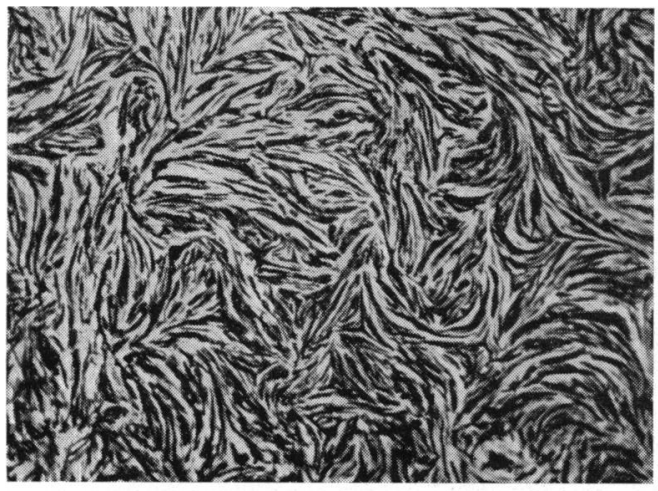

FIG. 1.-Flat section through inner limiting membrane of retina exhibiting coarse foot-plates of Müller's radial fibres. The substance of the inner limiting membrane is not stained. Frozen section, Hortega technique, photomicrograph. $\times 550$.

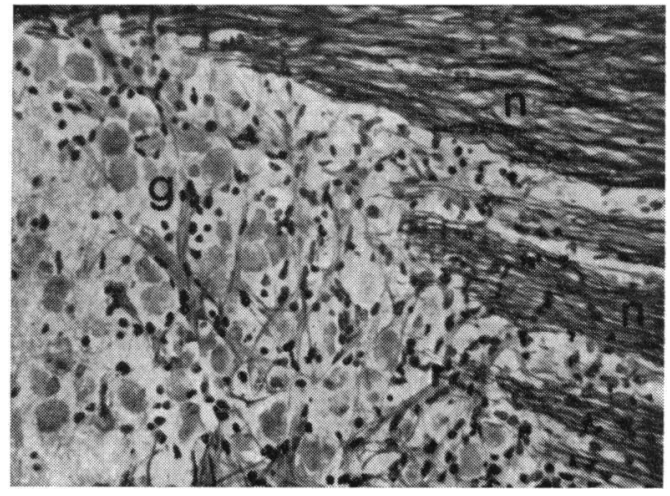

FIG. 2.-Transitional flat section of retina between fovea and optic disc showing fat-filled ganglion cells (g) and somewhat atrophic nerve fibre layer (n). Frozen section, Hortega stain, photomicrograph. $\times 130$.

Fig. 3 shows another flat section through the nerve fibre layer close to the disc with the neurites running upwards in the photograph. It is important to note the single neurite (arrow) which runs through the photographed area at 90 degrees to the main course of the nerve fibres.

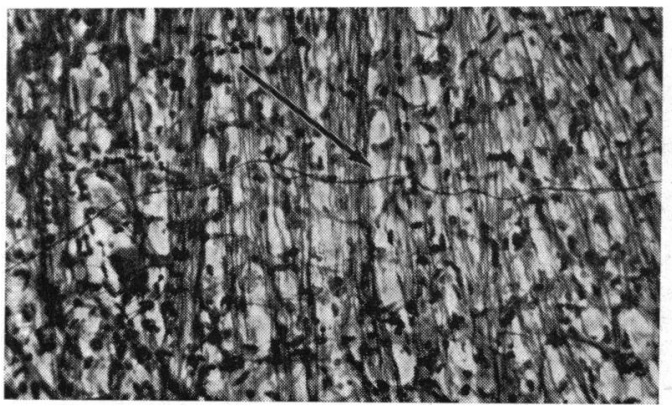

Fig. 3.-Flat section through nerve fibre layer next to optic disc with one nerve (arrow) running across the main course of the nerves from and to the optic disc. Frozen section, Hortega stain, photomicrograph. $\times 130$.

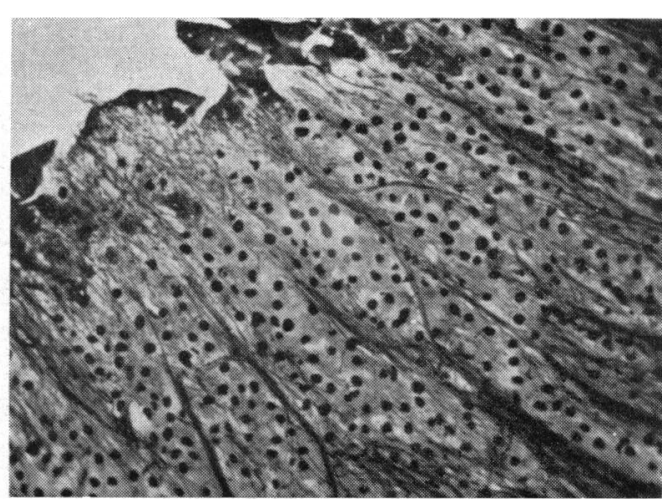

FIG. 4.-Flat section through swollen denselyarranged ganglion cells next to the fovea. Darkstained parts of inner limiting membrane are seen in left upper corner. Frozen section, Hortega stain, photomicrograph. $\times 130$.

(2) The densely-arranged swollen ganglion cells next to the fovea are seen photographed from a flat section through this area in Fig. 4. It has to be emphasized that all these cells stain a light red with the fat stain due to a lipoid material that they contain. The retinal astroglia is only slightly stained in Fig. 4. 
A good combined stain of astroglia and ganglion cells next to the fovea is seen in Fig. 5 . The retinal astroglia is hyperplastic all through the retina. Its nuclei are increased in number and its glial fibres form dense hyperplastic networks among the decreased number of swollen ganglion cells (Fig. 6).

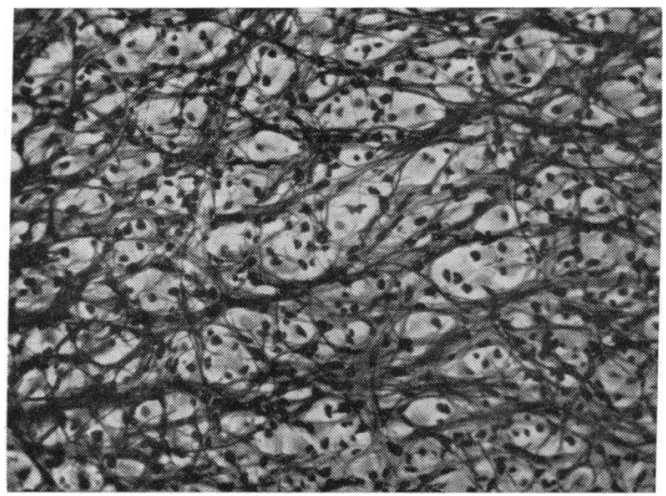

FIG. 5.-Flat section after combined stain showing fat-filled ganglion cells and hyperplastic astroglia next to the fovea. Frozen section, Hortega stain, photomicrograph. $\times 130$.

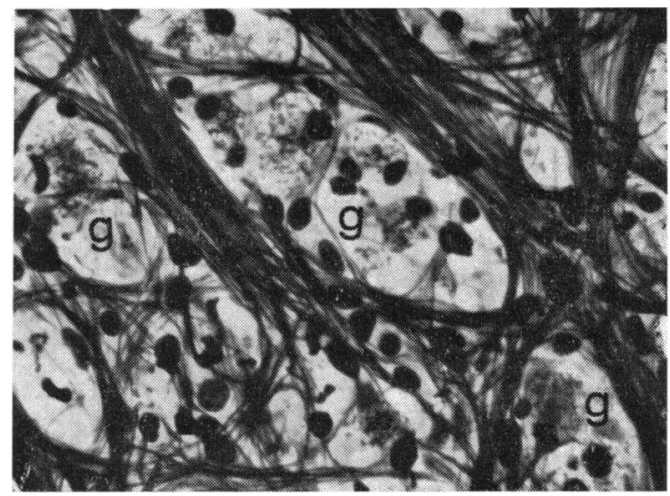

FIG. 6.-High-power view of swollen ganglion cells (g) surrounded by hyperplastic astroglia in the retina between the disc and fovea. Frozen flat section, Hortega stain, photomicrograph. $\times 550$.

(3) Fig. 7 shows two swollen ganglion cells (arrows) from the retina close to the optic disc surrounded by hyperplastic retinal astroglia. The arrangement of the glia suggests that a whole group of ganglion cells around each of the remaining cells has already degenerated and completely disappeared. The shape and structure of the remaining cells also indicate advanced degeneration. The cells have about twice their normal size. Their protoplasm has lost its normal architecture and contains many small vacuoles which appear empty. The nucleus is pushed from the centre to one side of the cell body.

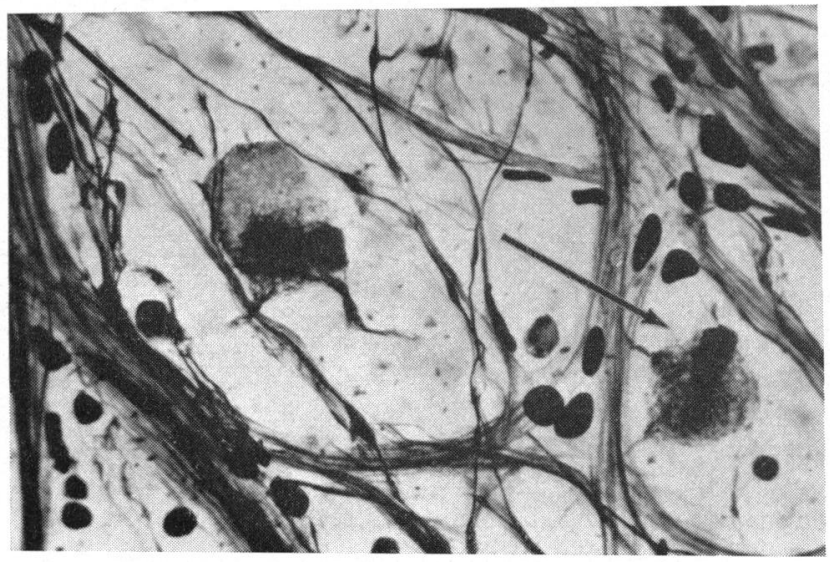

Fig. 7.-Two fat-filled degenerating retinal ganglion cells (arrows) in two glial meshes which would normally contain many ganglion cells. Frozen flat section, Hortega stain, photomicrograph. $\times 750$.

(4) The amacrine cells of the retina are involved in the lipoidal degeneration of the ganglion cells in the present case. However, the degenerative process is less advanced in these cells. Two swollen amacrine cells filled with lipoid substance, but with intact cell membranes, nuclei, dendrites, and neurites are seen in Fig. 8 ( $a, b$, opposite).

The formation of bizarre nodular swellings and obtuse oak-tree like branching of dendrites (arrows) of an amacrine cell as well as loss of a distinct cell membrane of a degenerating 


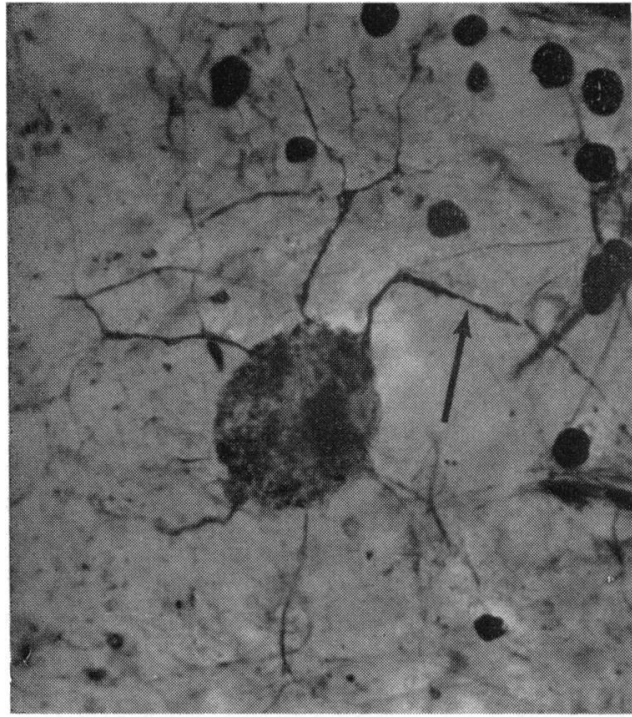

(a)

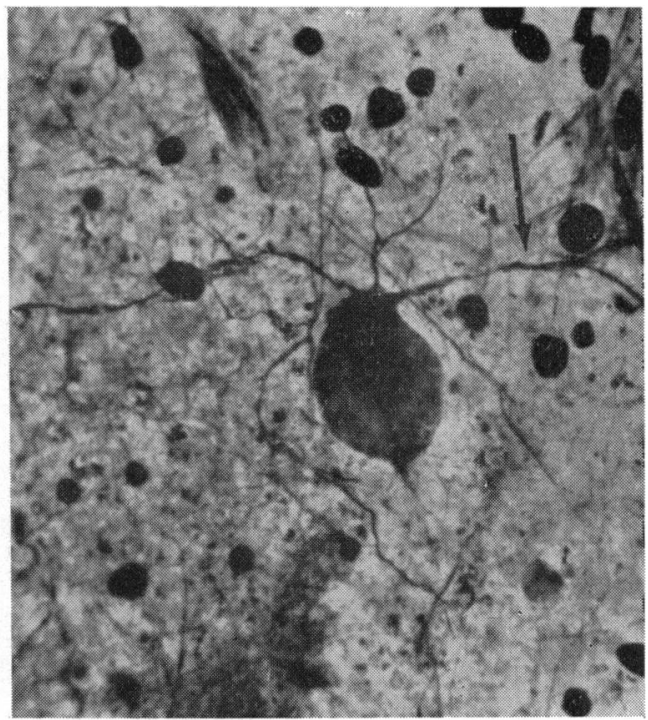

(b)

Fig. 8( $a, b)$.- Swollen retinal amacrine cells with many dendrites and a branching neurite (arrows). Frozen flat sections, Hortega stains, photomicrographs. $\quad \times 825$.

amacrine cell (a) are seen in Fig. 9. Two more advanced stages of the degeneration of the same cell type ( $b$ and $c$ ) are also seen in Fig. 9: the remains of one such cell still have a nucleus $(b)$ while only a faintly-staining "shadow" $(c)$ is the final stage of degeneration before total disappearance.

FIG. 9.-One swollen retinal amacrine cell $(a)$ with bizarre changes of its dendrites (arrows), a second amacrine cell (b) that has lost membrane and processes, and a third cell $(c)$ of which only a "shadow" remains. Frozen flat section, Hortega stain, photomicrograph. $\times 825$.

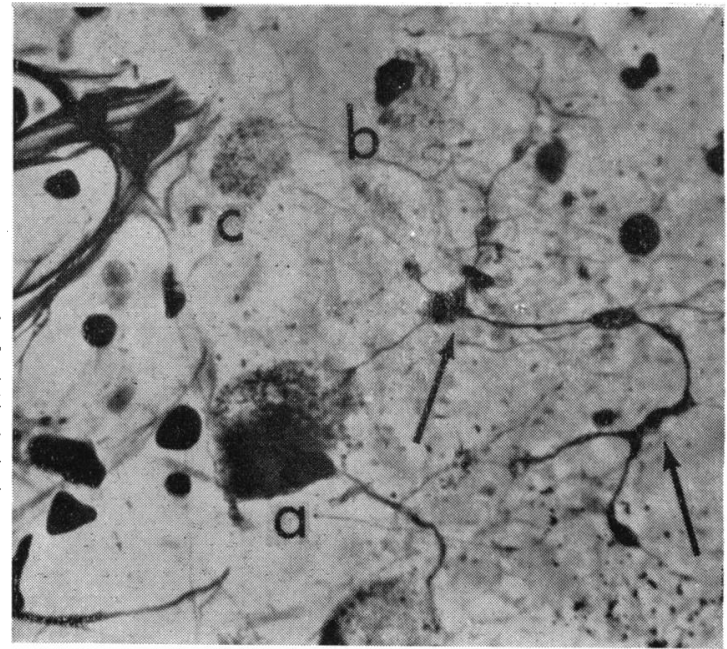

(5) Figs 10 and 11 (overleaf) show the final stages of degeneration in the cells of the ganglion cell layer. First these cells lose their cell membrane-almost as if they explode by accumulation of too much lipoid (Fig. 10). The nucleus and the cell processes still remain after the cell membrane has disappeared (Figs 10 and 11). Then the nucleus and the cell processes also slowly disappear (Fig. 11). 


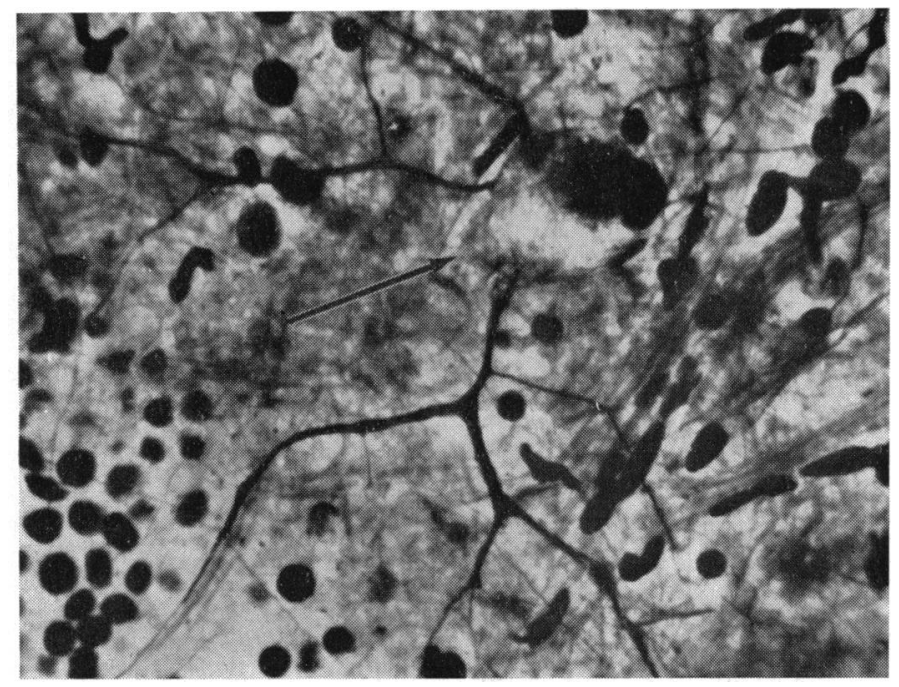

Fig. 10.-Fat-filled retinal ganglion cell that has lost its membrane (arrow). Frozen flat section, Hortega stain, photomicrograph. $\times 775$.

Fig. 11.-Retinal ganglion cell that has lost its membrane and its cytoplasmic structures (arrow). Nucleus and processes still remain. Frozen flat section, Hortega stain, photomicrograph. $\times 775$.

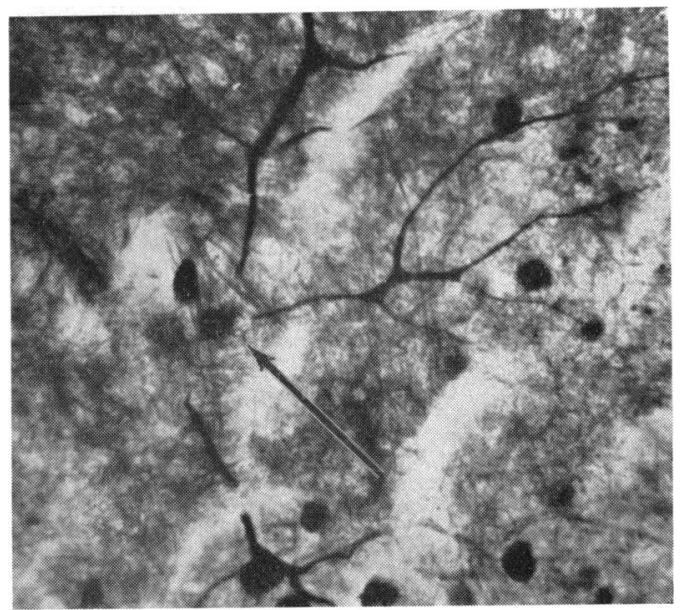

(6) No pigment is found deposited around the blood vessels as is observed in cases of retinitis pigmentosa. The migrating pigment in the present case is found deposited in the outer retinal layers (Figs 12 and 13, opposite). Definite pathology is observed in Henle's fibre layer around the fovea. The short neurites which form Henle's fibre layer are decreased in number and the remaining fibres are thickened and of an irregular course (Fig. 12). All rods and cones are missing in the foveal area and in the periphery. The remaining rods and cones in the posterior retina are scarce and show all stages of degeneration (Fig. 13). Most of the visual processes are thickened, distorted, and of non-distinct outlines. Some appear as pale-staining diffuse shadow-like processes, and most have completely disappeared.

\section{Discussion}

This new view of the details of retinal pathology in the late infantile type of amaurotic idiocy with neurohistological methods adds to the understanding of the disease. This morphological study does not, of course, explain the disease, but it shows the sites and the pattern of its effect in the retina. Even the advanced changes 


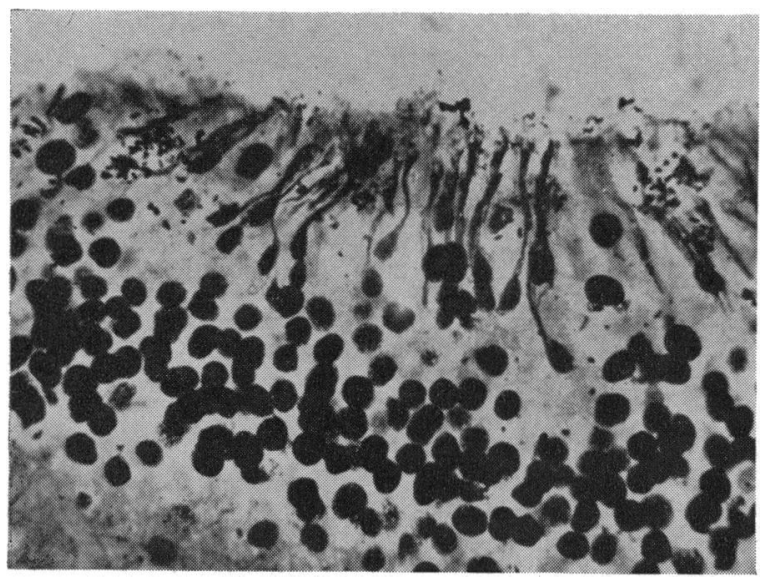

Fig. 12.-Scarce and degenerating Henle's fibres with pigment granules deposited around them in the foveal area. Frozen flat section, Hortega stain, photomicrograph. $\times 600$.

Fig. 13.-Scarce and irregular rods and cones with pigment granules deposited diffusely around them from from the retina between the disc and fovea. Frozen section, Hortega stain, photomicrograph. $\times 600$.

of the present case allow for the conclusion that the retinal changes have a double pathological mechanism as their cause. One part of the retinal involvement centres in the cytoplasm of the ganglion cells and there leads to accumulation of lipoid substances as well as to final destruction of these cells. Another-and probably not directly related-part of the retinal pathology involves the outer retina and may well have its real origin in the pigment epithelium.

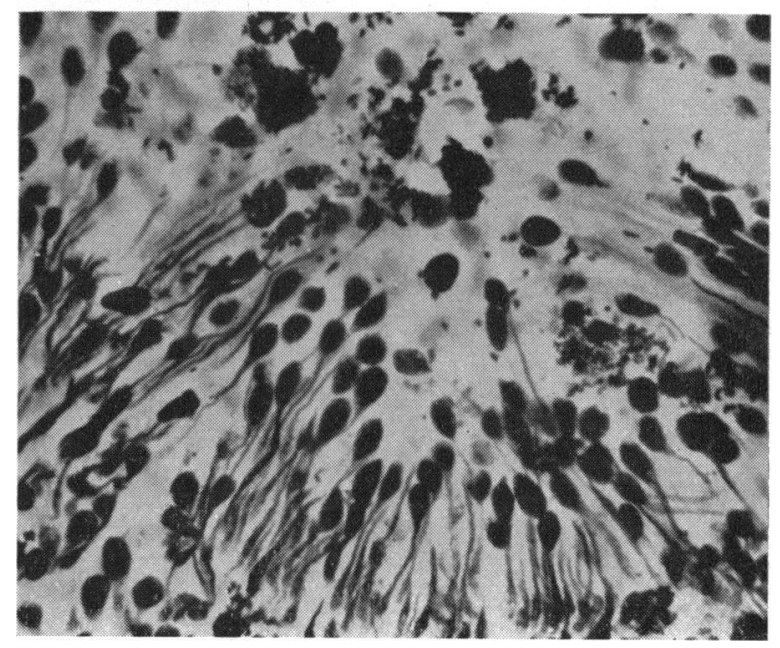

Several of the neurohistological details observed in this study deserve a brief discussion. It is common in all kinds of diseases that lead to atrophy of the inner retina to see a thick inner limiting membrane and coarse inner processes of Müller's radial fibres. The distinct decrease in the number of neurites in the nerve fibre layer is probably due to the atrophy of most of the corresponding ganglion cells because of the lipoidal degeneration. The fact of the presence of those nerves that run in different directions from the main course directly to and from the optic disc in this case is of special interest to us. We now have evidence that these nerves are branches of centrifugal (efferent) nerves. Their presence in this case is one of the definite indications that the centrifugal retinal nerves are not involved in this disease.

The accumulation of lipoid substances in the ganglion cells is without doubt the specific pathological feature of the disease. The observation of the many stages of swelling and degeneration gives an impression of the sequence of the ganglion cell changes as they must take place in the disease process. The cytoplasm first becomes to an increasing degree replaced by lipoid substance. The normal cytoplasmic architecture disappears, the nucleus is pushed from the centre to one side, and the 
cell body swells. Then the cell membrane disappears-it may be that it actually bursts. The cell processes and the nucleus remain for some time after the cell body has dissolved. Some cells on the inner limit of the outer nuclear layer are involved in the lipoidal degeneration. We believe that in our case these cells are amacrine (cf. Hagedoorn, 1940).

The deposition of lipoid substance in the densely-arranged swollen ganglion cells around the fovea must be the cause of the whitishness (halo) of this area of the retina that makes the fovea appear as a "cherry-red spot". This halo is less white than that seen in Tay-Sachs disease, since many of the ganglion cells are totally degenerated in the present condition and there is less contrast because of pigment deposition in the fovea. The retinal astroglia shows extensive hyperplasia and scar formation. This is to be understood as a non-specific reaction to fill the space of the degenerated ganglion cells.

The pathology that leads to degeneration of the pigment epithelium, the rods and cones, and Henle's fibres appears to be non-specific. Exactly the same changes are known from many other diseases. The involvement of Henle's fibre layer was demonstrated by Goldstein and Wexler (1931) in Niemann-Pick disease with cherryred spot of the macula. It may be emphasized that all the pigment granules which migrate into the retina remain in the outer layers and do not reach the inner retinal layers to be deposited around the blood vessels - as in retinitis pigmentosa.

The present morphological study adds to our knowledge of the rare form of the late infantile type of amaurotic idiocy which is characterized by a cherry-red spot and. of the neuropathology of the retina in general. Other approaches will be needed to explain the generalized defect that causes amaurotic idiocies.

\section{Summary}

The retinal neuropathology is demonstrated in the eyes of a child with advanced late infantile familial amaurotic idiocy using a silver technique. The retinal pathology includes the specific lipoidal degeneration of the ganglion cells and the nonspecific degeneration of the pigment epithelium and rods and cones. Morphological details have been reported and photographed.

\section{REFERENCES}

Batten, F. E., and Mayou, M. S. (1915). Proc. roy. Soc. Med., 8, Sect. Ophthal., p. 70.

BIELSCHOWSKy, M. (1913). Disch. Z. Nervenheilk., 50, 7.

DUKe-ElDER, W. S. (1940). "Text-book of Ophthalmology", vol. 3, p. 2805. Kimpton, London.

ELWYN, H. (1953). "Diseases of the Retina", 2nd ed., p. 336. Blakiston, New York-Toronto.

FrançoIs, J. (1961). "Heredity in Ophthalmology", p. 555. Mosby, St. Louis.

GIVNER, I., and RoIzIN, L. (1944). Arch. Ophthal. (Chicago), 32, 39.

GOLDSTEIN, I., and WEXLER, D. (1931). Ibid., 5, 704.

Hagedoorn, A. (1940). Amer. J. Ophthal., 23, 735.

Holmes, G., and Paton, L. (1925). Trans. ophthal. Soc. U.K., $45,447$.

MacMillan, J. A. (1948). Amer. J. Ophthal., 31, 1567.

SCHARENBerg, K., and Zeman, W. (1952). Arch. Psychiat. Nervenkr., 188, 430.

SORSBY, A. (1958). "Systemic Ophthalmology", 2nd ed., p. 464. Butterworth, London.

SPIELMEYER, W. (1906). Neurol. Zbl., 25, 51.

STOCK, W. (1908). Klin. Mbl. Augenheilk., 46, (1), 225 (n.s. 5).

Wolter, J. R. (1957). A.M.A. Arch. Ophthal., 57, 539. 